\title{
Neglected nursing responsibility when suspecting child abuse
}

\author{
Kari Skarsaune, Terese Bondas * \\ University of Nordland, Faculty of Professional Studies, Norway
}

Received: October 22, 2015

Accepted: November 19, 2015 Online Published: November 30, 2015

DOI: $10.5430 / \mathrm{cns} . v 4 \mathrm{n} 1 \mathrm{p} 24$

URL: http://dx.doi.org/10.5430/cns.v4n1p24

\begin{abstract}
Background: Child abuse is a serious global problem with long-lasting consequences for the child and his/her family. Nurses are in a position to stop the abuse, to detect and initiate care. The aim of this study was to describe nurses' experiences when they had suspected child abuse in their encounters with children and their families in various health care contexts. Child abuse is understood as a lack of care, neglect, physical or psychological, and sexual abuse according to World Health Organization and previous research.

Methods: Descriptive exploratory research design that uses content analysis. Eight nurses were interviewed individually and were chosen to represent a strategic sample of Norwegian health care units.

Results: The responsibility of the nurses was challenged and in many cases neglected when child abuse was suspected by the nurses. The child and his or her family lingered heavily in their minds regardless of whether they had acted on their suspicion or not. They doubted what they saw and what it meant, and they feared the consequences for the child and the family when acting on their suspicion. The fear of consequences included themselves. Uncertainty and anxiety haunted the nurses, and they felt little support for their actions from their colleagues and leaders. The nurses felt that their knowledge of the signs of child abuse, documentation and report routines was insufficient.

Conclusions: Nurses need to raise their awareness, responsibility, and courage to act when they encounter suspected child abuse. Nurses therefore need more knowledge about child abuse but also ethical reflection, collegial and management support, and interprofessional collaboration.
\end{abstract}

Key Words: Nurse, Nursing responsibilities, Children, Child abuse, Child maltreatment, Neglect, The battered child syndrome

\section{INTRODUCTION}

Nurses may encounter child abuse in their clinical nursing practice in different health care settings but this easily remains unnoticed as it may appear vague and difficult to detect. Child abuse can be physical, psychological, sexual and/or neglect of a child where the acts or omissions of action damages the child or endangers the child's health and development. ${ }^{[1]}$ This definition is supported by the $\mathrm{WHO}^{[2]}$ and $\mathrm{UN}$ Convention on the Rights of the Child (CRC), ${ }^{[3]}$ the Convention is to ensure that all children receive protection and healthy development. The CRC has been ratified by most countries in the world with Norway, the site of this study, joining the agreement in 1991. Child abuse exists in all cultures and is therefore a global problem.

\subsection{Background and significance}

There are various forms of child abuse. Physical child abuse includes all kinds of violence causing physical harm to a

\footnotetext{
*Correspondence: Terese Bondas; Email: terese.bondas@uin.no; Address: University of Nordland, Faculty of Professional Studies, Universitetsalleen 11, 8026 Bodö, Norway.
} 
child, from bruising to brain damage. Sexual abuse involves sexual intercourse with a minor, or forcing or enticing a child to take part in sexual activities. Emotional abuse is persistently degrading, threatening, or treating the child in any way that is harmful to the child's self-esteem. Child neglect is the persistent failure to meet a child's basic psychological or physical needs, such as food, clothing, and care. Care includes demonstrating that one cares, and encouraging and supporting the child. ${ }^{[4]}$

Child abuse is not a new phenomenon, but the view of what is or is not child abuse varies between different cultures and generations. What is understood in a society to be violence today may have been defined differently by previous generations and in other cultures. The fact that concepts and definitions vary can provide negative consequences for those subjected to abuse and can cause confusion for health care professionals and researchers. ${ }^{[5]}$ The first article describing "the battered - child syndrome" was published in 1962, the article describes the damage and injury mechanisms and how child abuse can be disclosed. ${ }^{[6]}$ Kempe et al. stress that nurses' observations are important in uncovering child abuse. Figures from Statistics Norway ${ }^{[7]}$ show that more than 52,000 cases are reported to the CPS every year and around $6 \%$ of the reports come from doctors, hospitals and dentists. It has not been possible to find statistics related to how many are signed by a nurse.

A major survey of graduates (7,033 young people) in Norwegian secondary schools reveals that between $16 \%-25 \%$ of the youngsters had experienced abuse, violence or witnessed violence in the family to a mild or severe degree. Poor family economy and alcohol problems amongst adults and minority backgrounds were linked to an increased risk. ${ }^{[8]}$ These are risk factors supported by the Finnish guidelines for clinical practice: identification of and intervention in child abuse. ${ }^{[9]}$ Tingberg ${ }^{[10]}$ has surveyed all children in Sweden who were admitted to hospital between 2005-2008 with diagnoses that could be compatible with child abuse. He found 301 children with such diagnoses, 137 of these qualified as genuinely suspicious. Forty-two of these children were suspected to have been sexually abused, and, of these, $62 \%$ were reported to the child welfare service. Physical violence was suspected in the remaining 95 children, and $51 \%$ of these were reported to child welfare.

Several countries have exposed child abuse in media reports, often occurring when something does not work or something has gone wrong. Abuse, lack of procedures, or procedures not followed will be reviewed and criticized publicly; this can be a difficult process for those involved. It is important to increase awareness of this issue. At the same time, this may also influence health workers making them reluctant to choose child welfare. ${ }^{[11]}$ The damaging effects of child abuse and the child's present and future health are well-documented. The extensive ACE - study (The Adverse Childhood Experiences) finds a clear correlation between disease later in life and early death among those who have experienced child abuse. ${ }^{[12]}$ Kirkengen ${ }^{[13]}$ has shown how offence in childhood may lead to substance abuse and somatization in adulthood. Research has also shown that trauma (toxic stress) in young children can interfere with brain development and cause damage and learning disabilities. ${ }^{[14]}$

Child abuse has been described as emotional and difficult for all involved including nursing practice, and there is a need for counseling, training and better cooperation within hospitals and between departments. ${ }^{[15,16]}$ Cowardice, work pressure and lack of knowledge about this serious problem hampers the identification of child abuse. ${ }^{[17]}$ Neglect in caregiving is the type of child abuse that is most often observed. Head injuries are most frequently reported. ${ }^{[18]}$ A Finnish cross-sectional survey of public health nurses regarding their identification of child abuse and subsequent intervention finds that physical abuse is easier to detect and report. ${ }^{[19]}$ Lack of knowledge and training of nurses recur as common threads in several studies. ${ }^{[17,18,20]}$ In Norway a report from 2007 shows that health and social work education does not include domestic violence as a topic on the regular curriculum. It is then up to the individual educational institution whether or not the subject is illuminated. ${ }^{[21]}$

Several countries have developed guidelines on how to reveal and treat child abuse. Finland has guidelines prepared especially for nurses, and these guidelines may benefit other health care professionals. The guide focuses on risk factors and how to proceed in case of suspicion. ${ }^{[9]}$ The United Kingdom's guidelines (2009) strive to increase health care professionals' awareness of their duties and functions with abused children and their families. ${ }^{[22,23]}$ Norway has an electronic handbook on physical abuse, which specifically targets those working in somatic specialized health services with assessment, diagnosis and follow-up of children who may have been subjected to abuse. ${ }^{[24]}$ This handbook is aimed at doctors, but is also useful for nurses. In Norway, a supervision authority is responsible for preventing sexual abuse of children. ${ }^{[25]}$ Lundén ${ }^{[26]}$ has studied how to identify neglect among Swedish pre-school children. She has also later written a book based on the dissertation. Here she describes, amongst other things, how to reveal neglect, the consequences for the child, and how nurses experience suspected child abuse. ${ }^{[27]}$ A tutorial was published on uncovering domestic violence in dialogues. ${ }^{[28]}$ 
The guidelines are not sufficient for nurses to detect and report child abuse. Feng and $\mathrm{Wu}^{[29]}$ find that knowledge and general attitude in the department are important for the nurse to report to child welfare. An Australian study also finds that attitudes have an impact. ${ }^{[30]}$ Joughin $^{[31]}$ examined how emergency staff can work in teams to protect children in the emergency room, which is an arena where child abuse may be detected. It appears that the lack of cooperation between agencies and poor communication are often mentioned as a cause of failure in child welfare cases. Nurses experience an ethical dilemma and a difficult dual role which they are not prepared for according to Tingberg. ${ }^{[16]}$ They provide care and should also be the persons who notify child protection when they suspect child abuse.

In summary, previous research shows that child abuse is a difficult subject field from a nursing perspective and can be hard to detect. There is a need for better interdisciplinary collaboration, training, guidance and support. We also know that both the nurses' attitudes and the general attitude in the health care unit are significant in reporting child abuse. Norway and several other countries have a statutory duty to report suspected child abuse, but few issues of concern are reported to child protection authorities. There is still scarce knowledge from a nursing perspective of encountering child abuse in nursing practice. This study is part of a larger research program, illuminating how nurses encounter child abuse in hospitals and health care centres. It is important to increase understanding and to develop ways of intervening in order to prevent child abuse and improve care for the children, who are indeed the victims.

\subsection{Objective}

The aim of this study was to describe the nurses' experiences when they had suspected child abuse in their encounters with children and their families in various health care contexts.

\section{Methods}

A qualitative content analysis ${ }^{[32,33]}$ was chosen for this study because this approach is considered suitable for investigating people's experiences, practices, thoughts, expectations, motives, and attitudes. We chose individual qualitative interviews; an interview approach that is unstructured and not predefined. ${ }^{[34]}$ As the topic is sensitive and the focus is here on identifying the nurses' experiences, individual interviews were considered more appropriate than focus group interviews.

\subsection{Setting and sample}

Informants were chosen through a strategic selection process. The criterion for participation was that the nurse had experienced situations where child abuse was suspected. Informants were selected from both children's units as well as other units. It was considered important to include nurses who were not primarily working with children, but in environments where children were part of a larger context. This choice was expected to give the study a broader and more comprehensive perspective of the nurses' experiences. The structure within hospitals varies. Major hospitals usually have specific children's units and admittances, while smaller hospitals tend to have units that include both children and adults. The process of finding informants started in the spring of 2011 by sending a request, via email, to the management of several hospitals and emergency rooms. The email included information about the project and an application for permission to conduct interviews. The management was requested to forward the inquiry to the relevant departments. Following approval, the managers of relevant departments were contacted. Some showed no interest and believed that the problem was not relevant for nurses in their department, while others responded positively. Based on this, we made a strategic selection that included eight nurses from different units and with different backgrounds. The nurses were between 35 and 60 years of age, and they all had extensive work experience, that is to say more than ten years' experience. The final sample provided a good basis to shed light on the problem from different contexts. The following units were represented: a children's ward, children's admission, casualty admittance, and municipal casualty. Two different hospitals (one university hospital and one small hospital) and a municipal casualty (medium-sized city) were also represented.

\subsection{Data collection}

The individual semi-structured research interviews ${ }^{[34]}$ were conducted by the first author, during the autumn of 2011 at the informants' workplaces. Both researchers are nurses with experience of encountering child abuse in their previous nursing practices, and had several reflective discussions on this vulnerable topic, trying to uncover own biases throughout the research process. One of the decisions that emerged was to choose individual interviews instead of focus groups due to the sensitive nature of child abuse and also to include general nursing units where child abuse may remain unnoticed.

The informants themselves arranged the places where the interviews took place. One interview was conducted outside the workplace. The interviews lasted from 30 minutes to 1 hour and 15 minutes, but most of the interviews lasted for about one hour. Several of the informants had worked with the issue of child abuse in different contexts, which contributed to providing the data with a thoughtful and reflective 
content. An interview guide (topic list) for interviews was prepared. It was made clear that informants could speak as freely as possible in order not to overlook important information. The interview guide was, therefore, used to ensure that all relevant topics were covered. The interviews were recorded in audio files and then transcribed verbatim. The interviews were transcribed by the researchers themselves, and provided useful input to the analytical process. ${ }^{[34]}$ In total there were 75 pages of transcribed data.

\subsection{Data analysis}

The data was analyzed using qualitative content analysis. This method, which utilizes a descriptive approach, is widely used in nursing research. ${ }^{[32]}$ An inductive analysis based on the informants' experience of the phenomenon was used, and the coded categories were sourced directly from the data. ${ }^{[33]}$ The analysis is based on a latent approach, which interprets the underlying meaning of the text. ${ }^{[32]}$

After transcription of the interviews, the text was read through, and then the text was divided into meaning units. A meaning unit is a word, a sentence, or a paragraph which is linked because of its contents or context. ${ }^{[32]}$ There were 425 meaning units that were numbered and traced back to their original context. They were first divided into three groups (nursing, children, and collaborators). The "nursing" group was, by far, the largest. The meaning units were then grouped into charts according to the content (16 groups). The meaning units were then condensed and entered into an Excel spreadsheet. "Condensed" means shortening the text so that the core of the content is preserved. ${ }^{[32]}$ Furthermore, during this process codes were developed. This involved abstracting the content to a higher logical level. A code can also be described as a label for the condensed meaning unit: something that requires abstraction. ${ }^{[32]}$ The analysis proceeds further from codes to sub-themes, and then themes that make up the findings. A theme is a collection of codes that have a similar content. The difference between a sub-theme and a theme is the level of abstraction; it gradually becomes more abstracted at each level. ${ }^{[32]}$ And finally, an overarching main theme was found.

\subsection{Ethical considerations}

The project was approved by the Norwegian Social Science Data Services (NSD). Participation in the project was voluntary and the participants received prior oral and written information about the project. All interviews started with verbal information about the project and the possibility of withdrawing at any time. None of the informants withdrew during the study and all signed consent forms. Data was anonymized so that neither the informant nor the examples

Published by Sciedu Press used could be recognized.

\section{Results}

Participants in the study were all female nurses with more than ten years of nursing experience from different contexts. They had all experienced situations where child abuse had been suspected. The overarching theme that emerged from the analysis is: "The responsibility of the nurses is challenged when suspecting child abuse" - based on four themes. The nurses doubted and found it difficult to recognize the signs of child abuse, and they had experienced the importance of collecting evidence in documentation and they lacked report routines. They pondered about the consequences for the child and the family - and for themselves. The vague and unclear situations, and the encounters with children and their families lingered heavily in their minds whether they had acted on their suspicion of abuse or not. The nurses looked for knowledge and longed for support to act.

\subsection{Doubting the signs of child abuse}

The nurses found it difficult to define child abuse and recognize the signs. There was no disagreement when it comes to serious physical abuse or sexual abuse, but there is considerable controversy regarding what the nurses describe as less severe. They often do not even know where the boundary lines are. When it comes to neglect, nurses find that there are even more grey areas and the definition is even more complex. They find it difficult, therefore, to know when there is reason for concern. One respondent expressed this conundrum as follows:

“... That is the question. When should the bells ring? When is there reason for concern? ... That is what is so hard to know ..." (Aase)

All informants talked about a gut feeling telling them that something was not right, but without being able to put their finger on it. It is difficult to know what is behind the gut feeling, but it does describe the uncertainty many feel. This uncertainty was expressed as follows:

"It's like ... we weigh it back and forth a lot, what is right, and should we trust what we think, or should we trust what parents say, or should we ... yes ... all in all ..."(Gerd)

\subsection{Collecting evidence in documentation and lack of re- port routines}

The procedures for reporting created uncertainty amongst nurses. For many it is unclear how they should proceed with the reporting. There is also uncertainty about who should report cases of child abuse. Everyone knows that they can 
make a report on their own initiative, but being aware that one can make a report is a long way from actually submitting a report. None of the nurses had ever reported child abuse without the consent of a doctor or a manager. The nurses said that they would prefer to report through a responsible agent, such as a doctor or a manager. The problem arises when nurses are not supported with regard to their suspicions. What then? One nurse puts it this way:

"The doctor engages with the family and almost always comes out not supporting me. We rarely agree. Then I end up in a dilemma ... and what unfortunately happens next, is that I do nothing ... We don't have guidelines ... it would be easier if we had." (Eli)

Documentation, also, created uncertainty and fear among nurses. How should they document the abuse for it to be legally valid? Meanwhile, the study also revealed that there is a fear of documenting too much. Documentation links the nurse to the case, which they could be confronted with in retrospect.

“... many are afraid about documenting too much in the patient record ... we have experienced that the witnesses in the trial were picked out after they had documented ..." (Aase)

The participating nurses wished to have guidelines when they face insecurity. A "sandwich list" of what can/should/must is considered and how to act to help the child is something the nurses would like.

\subsection{Pondering about the consequences for the child and the family - and for themselves}

Feeling that the nurses could be wrong is there all the time. This worries nurses and causes insecurity and anxiety regarding the consequences to the family. Nurses also want to protect their own skin: Could it have consequences for their work situation? Could the family take "revenge"?

Knowing that no matter what is done and by reporting their suspicions, the nurses may damage the child and family. Nurses feel that they have great power and can destroy much. This power and the fear to destroy stop them from going ahead with reporting, "what if I'm wrong." (Eli and Mari) Nurses describe this as "painting the devil on the wall" or "crying wolf, wolf" (Aase) even if there are no wolves. Therefore nurses want better guidelines and more teaching in order to improve their assessments.

\subsection{Searching for knowledge and support}

Nurses experienced frustrations and difficulties when suspecting child abuse and when searching for knowledge. They felt abandoned by their colleagues if they did not support them and were never sure about what they see or what to think. It was difficult to confront parents on the basis of suspicions. The situation is perceived as conflicting and unclear.

"It's hard. As a mother I would not like to be confronted with suspicion. I would have gone on the defensive, and I think they also do. Therefore, I think ... we feel that we have to be 150 percent sure before we dare to confront the parents. I think it's one of the hardest confrontations we can make." (Mari)

Child abuse is experienced as emotionally challenging and triggers many feelings that nurses must deal with. These feelings can haunt them over time. Statements such as "have pondered a lot in hindsight (Eli)" - "cannot forget (Lisa)" "it does something to our feelings (Aase)" - "the whole spectra of negative emotions (Aase)" - "uncomfortable situation to be in (Mari)" - "unable to be objective (Brit)" suggest a lot about the emotional aspects. Nurses find it emotionally difficult regardless of whether they file a report or not.

The nurses feel a strong need to discuss the problem with someone because these are matters which are difficult to face alone. Different options were mentioned. Some wanted support from a leader who could guide them through the process, while others would like support from colleagues. Several wanted stronger cooperation with the school-nurse, kindergarten, and school. One proposal was the creation of a resource group across departments, which could offer assistance and support in relevant cases. "We can't manage alone” (Gerd) was a recurring complaint. And, they demonstrated a strong need for support when they suspect child abuse.

\section{Discussion}

Suspecting child abuse lingered heavily in the nurses' minds. The situation of the child and its family challenged their nursing responsibility, a deeply human caring responsibility in their profession. In this study, neglect of nursing responsibility had occurred. The ethical conflict emerged when they doubted what they saw and what it meant and not knowing how to act or when to act. Nurses also experienced a conflict between providing care to the child and to the family when they suspected child abuse. Documentation and report routines were unclear. The consequences for the child, the family, and even for themselves were unclear. Nurses in this study found child abuse to be a grey area in all aspects. When nurses suspect child abuse, they feel a strong need for support from their colleagues and the management. The situ- 
ation is unclear and characterized by uncertainty and anxiety. They did not want to act alone. The participating nurses had many thoughts and wishes about how the situation ought to be, but the vague and unclear aspects act like a clammy hand surrounding the situation, which makes the situation appear difficult. A heavy burden for nurses to bear is the awareness that whatever should be done could hurt the child and the family.

The WHO definition of child abuse is wide-ranging. When child abuse is difficult to define, nurses must use their professional judgment. Martinsen ${ }^{[35]}$ argues that certain aspects of professional discretion can contribute to making concrete rules that can be applied to individual cases. Rules based on common sense judgments are reminders of the values that should be applied to a specific situation. The individual nurse also uses personal human knowledge, experience, and understanding of the situation. Common sense is far more important than knowledge based on norms and rules. ${ }^{[35,36]}$ Reporting and handing over responsibility were desirable. The participating nurses avoided talking about encountering the child and his or her family. They were not prepared for this. The risk is evident that the child will continue to suffer if nurses do not dare encounter the child and the family in dialogues and observation in order to understand and act on behalf of the vulnerable child.

In addition, nurses require broad general knowledge about child development, communication, symptoms, and the characteristics of child abuse. This knowledge is important when child abuse is identified. For example, knowing what normal development is, and how to communicate without disengaging from the situation is important. According to Martinsen, ${ }^{[36]}$ knowledge and skills are prerequisites for good care.

Child abuse is a complex and multifaceted problem and nurses in this study found it murky and vague. The ethical and legal challenges turn into a balancing act between justice, autonomy, charity, and not causing harm. ${ }^{[37]}$ The danger of violations will always be there. Nurses, therefore, want to be totally sure before they report child abuse cases. An ethical challenge occurs in a situation where it may be impossible to be certain whether child abuse has actually occurred. Other studies also conclude that nurses are afraid of making mistakes. ${ }^{[38]}$ As the nurses described in this study, it is also the fear of consequences that prevents nurses from reporting. ${ }^{[39]}$ The nurses are afraid of parental retribution or work-related consequences. The same fear prevents them from documenting their suspicions; they do not want to get involved. Some nurses had been subjected to threats. This creates a climate of uncertainty and fear. Feng ${ }^{[15]}$ finds that teachers, doctors, and nurses fear that parents will retaliate

Published by Sciedu Press if they report child welfare cases. Therefore, nobody wants to be responsible for reporting child abuse. The nurses in this study would prefer that the report goes from the unit to the child protection authorities. When nurses are required to report directly, there is a worry that cases will not be reported due to the fear that they will become involved in the follow-up actions, such as a lawsuit.

Risk is closely associated with responsibility. Nurses will consider an action on the basis of negative and positive consequences according to Wallinvirta. ${ }^{[40]}$ Then they have to decide if they are willing to take the risk to involve themselves. Responsibility requires courage and daring to speak out in spite of different perceptions within the unit. The risk of getting involved requires the nurse to be strong. An easy way out might be that this is someone else's responsibility. This is where the nurse must take responsibility, which cannot be left to other people. Lindberg, Persson and Bondas ${ }^{[41]}$ have looked at responsibility in another situation. This study reveals that there is consensus, in this case on the importance of integrating research with practice, but it is perceived by nurses as someone else's responsibility. Do nurses feel the same way in relation to child abuse? Lindberg, Persson and Bondas ${ }^{[41]}$ find that clarification of responsibility is important. The individual nurses must know their responsibilities and accept responsibility. Nurses have both an ethical and a legal responsibility towards maltreated children, which they cannot escape; this is at the ethical core of nursing care. ${ }^{[40]}$ Nurses call for guidelines, but could this become a disclaimer? Good guidelines are important, but missing guidelines must not be an excuse not to care. The question is how nurses can have faith in their own judgment and feel confident when they suspect child abuse? Thinking and worrying on their own may be not be helpful. Courage to encounter the child and the family, to create a caring relationship in dialogues ${ }^{[40]}$ is an alternative, and in this study, hardly mentioned. Versatile knowledge and support is what the nurses themselves suggested.

Considering the consequences of child abuse on children in both the short and the long term, nurses must be aware of their responsibilities. Hence, nurses need to take personal responsibility, which will in turn depend on their ontological beliefs. ${ }^{[40]}$ Nurses can play an important role in helping children out of a difficult situation. Knowledge about the consequences of childhood trauma may contribute to increased responsibility and awareness amongst nurses. Although there will always be uncertainty, if nurses understand the consequences of child abuse, they will be more willing to act. This uncertainty is challenging and difficult. This is also the issue of risk. When responsibility is assessed against the risk, this may prevent nurses from taking responsibility. Their 
own fear and lack of knowledge restrict freedom and prevent nurses from doing their responsible deeds for the patients. ${ }^{[40]}$

Children need brave nurses who dare to become involved in situations with a questioning and open mind. Martinsen ${ }^{[36]}$ emphasizes the importance of nurses being inquisitive. When one questions, one dares to listen and be receptive to emerging issues. The ability to combine problem-solving and knowledge with questions contributes to an inquiring mind that is not overconfident, but is used purposefully for the benefit of the patient. ${ }^{[42]}$ When nurses meet families where their gut feeling tells them that something is not right, they must explore the situation. While nurses say they must dare to ask difficult questions and be inquisitive, they also say that this is difficult. Paavilainen, Åstedt-Kurki ${ }^{[43]}$ reveal a need for training in how to tackle such difficult and sensitive issues.

Nurses are in a unique situation when it comes to detecting child abuse. ${ }^{[20]}$ They do not represent the government authorities, and they are associated with care. Nobody reacts disapprovingly when a nurse moves around the bed of the patient. Thus, the nurse can get close to the patient, observe, and question. The nurses themselves in this study expressed that they need to be in the room with the child and observe what happens.

In difficult situations, psychological support is important. Nurses need support throughout the whole process in child welfare cases. The need for support is huge, but they do not always receive the support they need, as this study shows. Likewise, studies have shown that teachers and doctors who encounter suspicion of child abuse also want to discuss the matter with somebody else and, therefore, seek the support of the hospital social worker or school counsellor. ${ }^{[15]}$ Nurses seeking support from doctors often feel dejected if the doctors do not want to discuss the matter with them. This reluctance may be due to uncertainty and frustration amongst the doctors, as Feng ${ }^{[15]}$ points out. Poor communication and collaboration between professionals and agencies is also found in the study by Land and Barclay. ${ }^{[44]}$ Doctors and nurses must cooperate, support, and complement each other. Support is crucial to help nurses handle child abuse cases, both during and after the case. The person providing support to the nurses must be responsive, knowledgeable, trustworthy, non-judgmental, willing to listen, reliable, attentive, easy to talk to, accessible, and supportive. There is a need for experienced supporters that can provide training, guidance and emotional support when needed. ${ }^{[45]}$

\section{Limitations}

In the study, the interviews with the eight nurses contributed to a rich data set although the participants were only inter- viewed once. They were all experienced nurses with more than ten years of work experience, and were willing to describe their experience related to this sensitive issue that involved their own shortcomings in nursing care. The participating nurses had different backgrounds. Choosing participants with different perspectives provided a broad and deep understanding of the phenomenon. ${ }^{[32]}$ All nurses had varied experience of being in situations where child abuse was suspected. As part of the relevant selection strategy, a targeted and appropriate selection of informants had been made from different contexts. ${ }^{[46]}$ Eight informants were sufficient to achieve saturation of data material. ${ }^{[47]}$ Meanwhile, there will always be a question about how other informants would affect the study.

\section{Conclusion}

A core professional nursing responsibility is caring for and advocating for the vulnerable child. Based on the understanding gained from this study, this is not always fulfilled and neglect of nursing responsibility has occurred. Another challenging responsibility is maintaining the dignity of the family members even in situations where child abuse is suspected. Nurses need to overcome the fear of getting involved. There is also a need for better cooperation and understanding within hospitals and between different child welfare agencies. However, the most important requirement is to encourage nurses to take responsibility to act in these challenging situations. The study reveals a need for better training of nursing students and nurses. The topic needs not only to become part of the bachelor's degree program in order to improve the level of knowledge among nurses but also to raise their awareness by reflections.

Data was collected from various health care units, both where the main focus is children, and where the focus is divided between children and adults. Some of the unit managers told us that they did not have this problem and therefore could not see the point in participating in the study. This is a finding in itself that points to new research questions in this research programme. Parts of the data were taken from emergency and admittance departments where nurses often find themselves in acute situations. In such situations it is also important to be aware of possible child abuse in order to reveal it as early as possible. Early identification is important not only for the good of the child, but also for securing the evidence. Knowledge is needed how to uncover, how to report, and how to handle difficult situations. Nurses place a huge responsibility on management, including holding management responsible for training and the general attitude of the unit. There is, therefore, also a need for follow-up studies on management. The core of nursing care, how to improve 
the encounter and care for children and their families when child abuse is suspected, must always be kept strongly in mind.

\section{ACKNOWLEDGEMENTS}

The authors would like to thank the nurses who participated in this study. We want to thank Peter Glanfield for helping us with the English language.

\section{CONFLicts OF InTEREST Disclosure}

There are no conflicts of interest to report.

\section{REFERENCES}

[1] Chung US. It Is Time for Doctors to Start Seeing the Signs and Hearing the Cries of Abused Children as Professional Guardians. Journal of Korean Medical Science. 2015; 30(4): 351-352. PMID:25829799. http://dx.doi.org/10.3346/jkms.2015.30.4.351

[2] WHO. Child maltreatment. [Homepage WHO ] 2015 [cited 2015 july 12th]; WHO's definition of child maltreatment]. Available from: http://www. who.int/topics/child_abuse/en/

[3] UN. Convention on the Rights of the Child. 1989 [cited 2015 July 12th]; Available from: http://www.ohchr.org/en/professio nalinterest/pages/crc.aspx

[4] Lyden C. Uncovering child abuse. Nursing Management. 2011; 41: 15. http://dx.doi.org/10.1097/01. NURSE.0000396601.754 97.26

[5] Øverlien C. The Children of Patriarchal Terrorism. Journal of Family Violence. 2013; 28(3): 277-287. http://dx.doi.org/10.1007 /s10896-013-9498-9

[6] Kempe C, Frederic N, Silverman F, et al. The battered-child syndrome. JAMA. 1962; 181(1): 17-24. PMID:14455086. http://dx .doi.org/10.1001/jama.1962.03050270019004

[7] Statistics Norway. Statistic Child protection. 2015. Available from: https://www.ssb.no/statistikkbanken/selecttable/ho vedtabellHjem. asp?KortNavnWeb=barneverng\&CMSSubjec tArea=sosiale-forhold-og-kriminalitet\&checked=true

[8] Stefansen K, Mossige S. Violence and abuse against children and young people: A self-reporting study among senior high school students. NOVA - Norwegian Social Research. 2007; 20: 235 s.

[9] Paavilainen E, Flinck A. Identification of and intervention in child maltreatment. A clinical practice guideline. Nursing Research Foundation. 2008.

[10] Tingberg B. Child abuse - clinical investigation, management and nursing approach. Doctoral thesis. Karolinska Institute, Stockholm; 2010.

[11] Skellern CY. Child protection: A 50-year perspective. Journal of Paediatrics and Child Health. 2015; 51(1): 87-90. PMID:25534472. http://dx.doi.org/10.1111/jpc. 12813

[12] Felitti VJ, Anda RF, Nordenberg Dc, et al. Relationship of Childhood Abuse and Household Dysfunction to Many of the Leading Causes of Death in Adults: The Adverse Childhood Experiences (ACE) Study. American Journal of Preventive Medicine. 1998; 14(4): 245-258. http://dx.doi.org/10.1016/S0749-3797 (98)00017-8

[13] Kirkengen AL. The lived experience of violation: how abused children become unhealthy adults. Zeta Books. 2010. http://dx.doi . org/10.7761/9789731997476

[14] Shonkoff JP, Garner AS, Siegel BS, et al. The lifelong effects of early childhood adversity and toxic stress. Pediatrics. 2012; 129(1): e232e246. PMID:22201156. http://dx.doi.org/10.1542/peds. 20 11-2663

[15] Feng JY. Multidisciplinary collaboration reporting child abuse: A grounded theory study. International Journal of Nursing Studies.
2010; 47(12): 1483-1490. PMID:20570266. http://dx.doi.org /10.1016/j.ijnurstu. 2010.05.007

[16] Tingberg B, Bredlöv B, Ygge BM, et al. Nurses' experience in clinical encounters with children experiencing abuse and their parents. Journal of Clinical Nursing. 2008; 17(20): 2718-2724. PMID:18808640. http://dx.doi.org/10.1111/j.1365-2702. 2008.02353. $\mathrm{x}$

[17] Paavilainen E, Merikanto J, Åstedt-Kurki P, et al. Identification of child maltreatment while caring for them in a university hospital. International Journal of Nursing Studies. 2002; 39(3): 287-294. http://dx.doi.org/10.1016/S0020-7489(01) 00035-9

[18] Pabis M, Wronska I, Slusarska B, et al. Paediatric nurses' identification of violence against children. Journal of Advanced Nursing. 2011; 67(2): 384-393. PMID:20946570. http://dx. doi .org/10. $1111 / j .1365-2648.2010 .05473 . x$

[19] Paavilainen E, Helminen M, Flinck A, et al. How public health nurses identify and intervene in child maltreatment based on the national clinical guideline. Nursing research and practice. 2014. http://dx.doi.org/10.1155/2014/425460

[20] Keane C, Chapman R. Evaluating nurses' knowledge and skills in the detection of child abuse in the Emergency Department. International Emergency Nursing. 2008; 16(1): 5-13. PMID:18519048. http://dx.doi.org/10.1016/j.ienj.2007.11.006

[21] Sogn H. Teaching about violence at Universities and Colleges. Norwegian Centre for Violence and Traumatic Stress Studies, NKVTS 2007.

[22] Appleton JV, Glaser D. Suspecting child maltreatment. Community practitioner. 2009; 82(9): 34. PMID:19788123.

[23] NICE. NICE guidelines [CG89]. When to suspect child maltreatment. 2009. [cited 14.07.2015]. Available from: http://www.nice.org .uk/guidance/cg89/informationforpublic

[24] NKVTS. Manual for health workers on suspicion of physical child abuse. 2012 [cited 14.07.2015]. Available from: http://www.nkvt s.no/sites/barnemishandling/Pages/index . aspx

[25] Child sexual abuse: a guide for using the apparatus. Oslo: Sosial- og helsedirektoratet i samarbeid med Barne- og familiedepartementet; 2003.

[26] Lundén K. Preschool children who are abused. Doctoral thesis. University of Gothenburg, Department of Psychology. 2000.

[27] Lundén K. Identifying neglect in preschool children. Children's Welfare Foundation. 2010.

[28] Manual for conversation about domestic violence cases in health hospitals and health care. 2015. [cited 2015.08.27]. Available from: http://www. valdinararelationer.se/upload/V\%C3\%A5ld\% $20 \mathrm{i} \% 20 \mathrm{n} \% \mathrm{C} 3 \%$ A4ra\%20relationer. se/Christina/Handledn ing $\% 20 \mathrm{f} \% \mathrm{C} 3 \% \mathrm{~B} 6 \mathrm{r} \% 20$ samtal. pdf

[29] Feng JY, Wu YWB. Nurses' intention to report child abuse in Taiwan: A test of the theory of planned behavior. Research in Nursing \& Health. 2005; 28(4): 337-347. PMID:16028263. http: //dx.doi.org/10.1002/nur.20087 
[30] Fraser JA, Mathews B, Walsh K, et al. Factors influencing child abuse and neglect recognition and reporting by nurses: A multivariate analysis. International Journal of Nursing Studies. 2010; 47(2): 146153. PMID:19540493. http://dx.doi.org/10.1016/j.ijnur stu. 2009.05.015

[31] Joughin V. Working together for child protection A\&E. Emergency Nurse. 2003; 11(7): 30-7. PMID:14686200. http://dx.doi.org /10.7748/en2003.11.11.7.30.c7651

[32] Graneheim UH, Lundman B. Qualitative content analysis in nursing research: concepts, procedures and measures to achieve trustworthiness. Nurse Education Today. 2004; 24(2): 105-112. PMID:14769454. http://dx.doi.org/10.1016/j.nedt. 2003 .10 .001

[33] Vaismoradi M, Turunen H, Bondas T. Content analysis and thematic analysis: Implications for conducting a qualitative descriptive study. Nursing \& Health Sciences. 2013; 15(3): 398-405. PMID:23480423. http://dx.doi.org/10.1111/nhs. 12048

[34] Kvale S, Brinkmann S. The Qualitative Research Interview. Oslo: Gyldendal akademisk; 2009. 344 s.: ill.

[35] Martinsen K. Caring in nursing: a moral challenge. K. Jensen, Editor. Gyldendal: Oslo; 1990. 61-97 p.

[36] Martinsen K. Care and Vulnerability. Akribe. 2006.

[37] Feng JY, Chen YW, Fetcher S, et al. Ethical and legal challenges of mandated child abuse reporters. Children and Youth Services Review. 2012; 34(1): 276-280. http://dx.doi.org/10.1016/j.child youth. 2011.10 .026

[38] Eisbach SS, Driessnack M. Am I Sure I Want to Go Down This Road? Hesitations in the Reporting of Child Maltreatment by Nurses. Journal for Specialists in Pediatric Nursing. 2010; 15(4): 317-323.
PMID:20880280. http://dx.doi.org/10.1111/j.1744-6155. $2010.00259 . x$

[39] Piltz A, Wachtel T. Barriers that inhibit nurses reporting suspected cases of child abuse and neglect. Australian Journal of Advanced Nursing. 2009; 26(3): 93.

[40] Wallinvirta E. Responsibility as Sounding Board in the Caring's Context of Meaning. Doctoral thesis. Åbo Akademi University, Faculty of Education and Welfare Studies, Nursing Science. 2011. 241 p.

[41] Lindberg E, Persson E, Bondas T. The responsibility of someone else: a focus group study of collaboration between a university and a hospital regarding the integration of caring science in practice. Scandinavian Journal of Caring Sciences. 2012; 26(3): 579-586. PMID:22272695. http://dx.doi.org/10.1111/j.1471-6712. 2012.00968.x

[42] Martinsen K, Kjaer TA. Løgstrup and nursing care. Oslo: Akribe; 2012. $198 \mathrm{~s}$.

[43] Paavilainen E, Åstedt-Kurki P, Paunonen M, et al. Caring for maltreated children: a challenge for health care education. Journal of Advanced Nursing. 2002; 37(6): 551-557. PMID:11879419. http://dx.doi.org/10.1046/j.1365-2648.2002.02128.x

[44] Land M, Barclay L. Nurses' contribution to child protection. Neonatal Paediatric and Child Health Nursing. 2008; 11(1): 18.

[45] Rowse V. Children's nurses' experiences of child protection: what helps? Child Abuse Review. 2009; 18(3): 168-180. http://dx.d oi.org/10.1002/car.1073

[46] Elo SK, Kanste M, Pölkki O, et al. Qualitative Content Analysis: A Focus on Trustworthiness. SAGE Open. 2014; 4(1). http: //dx.doi.org/10.1177/2158244014522633

[47] Tjora AH. Qualitative research methods. Oslo: Gyldendal akademisk; 2012. 246 s.: ill. 